\title{
COPING WITH COVID-19: URGENT NEED FOR BUILDING RESILIENCE THROUGH COGNITIVE BEHAVIOUR THERAPY
}

\author{
Farooq Naeem ${ }^{\prime \otimes}$, Muhammad Irfan ${ }^{2}$, Afzal Javed $^{3}$
}

THIS ARTICLE MAY BE CITED AS: Naeem F, Irfan M, Javed A. Coping with COVID-19: urgent need for building resilience through cognitive behaviour therapy. Khyber Med Univ J 2020;12(I):I-3. DOI: 10.35845/ kmuj.2020.20194.

At the start of 2020 , originating from Wuhan city, coronavirus disease 2019 (COVID-I9) started to spread throughout China.' The World Health Organization has declared this to be a pandemic. ${ }^{2}$ Both healthcare workers and the general public have been experiencing psychological problems, including anxiety, depression, and stress, as a result of the rapidly increasing numbers of confirmed cases and deaths. ${ }^{3}$ Isolation strategies are used throughout the world to limit the spread of the virus. While these strategies are essential in protecting lives, isolation might add to the stress and is highly likely to lead to emotional health problems. ${ }^{4}$ It is difficult to predict the long-term physical and mental health consequences of COVID-I9. However, an economic crisis is highly likely to follow that might worsen the mental and emotional health problems across the nations. ${ }^{5}$ There is a need to develop and test evidence-based interventions that can help build resilient communities to help people cope with the current situation, deal with physical health issues as well as the personal trauma, and most importantly to prevent future emotional and mental health problems. Such intervention should also be low cost, easy to deliver in a variety of formats at a public health scale. We believe Cognitive Behaviour Therapy (CBT) is the ideal interventional tool to build resilience.

The philosophical origins of cognitive therapy can be traced back to stoic philosophers. Epictetus famously wrote in "The Enchiridion," "Men are disturbed not by things but by the view which they take of them." CBT originated with the formulation of a cognitive model of depressive illness, which evolved from systematic clinical observations and experimental testing. ${ }^{6}$ CBT is an active, directive, structured, and time-limited approach to treat a variety of problems. It is based on the principle that a person's emotions and behaviours are primarily determined by the way in which he perceives the world. The cognitions (thoughts) are based on assumptions or attitudes, developed from previous experiences. Therapeutic techniques are used to identify, reality test, and correct distorted thinking patterns and the dysfunctional beliefs underlying these thinking patterns. The therapist helps the patient to think and act more realistically and adaptively about his psychological problems and thus reduce symptoms. The cognitive model postulates three specific concepts to explain the psychological basis of depressive illness; (a) the cognitive triad i.e., what a person thinks about the self, others and the future, (b) dysfunctional beliefs i.e., beliefs that are formed during early development and are triggered when a person faces a challenging situation and the (c) cognitive errors. The common cognitive errors include; black and white thinking, jumping to conclusions, overgeneralization, minimization and magnification, personalization, selective abstraction and catastrophization. ${ }^{6}$

We all make "cognitive errors"; however, most of us can deal with these. A person with high levels of vulnerability to emotional or mental health problems or facing high levels of stress might fail to address their cognitive errors. It has
I. Professor University of Toronto \& Staff Psychiatrist, Centre for Addiction \& Mental Health, Toronto - Canada and Member Editorial Board KMUJ. Email凶: farooqnaeem@yahoo.com

2. Profesor, Department of Mental Health, Psychiatry \& Behavioural Sciences, Peshawar Medical College, Riphah International University, Islamabad, Pakistan and Member Editorial Board KMUJ

3. President-Elect, World Psychiatric Association; Consultant Psychiatrist at NHS \& Honorary Associate Professor, Warwick Medical School, University of Warwick-UK.

been suggested that when faced with a challenging situation, a person might catastrophize such as, "This is horrible, I am not going to survive Corona, or "What is the point. We all are going to die". They might then feel low, experience hopelessness, and stop attempting to keep themselves safe during the pandemic. In CBT, the therapist helps a person to identify their automatic, negative thoughts and unhelpful behaviours, and eventually modify the thoughts and behaviours. They specifically teach them empowering skills to help them manage the situation, help develop healthy coping skills and deal with their concerns such as isolation. However, CBT is not promoting positive emotions. So, rather than saying "don't worry, everything is going to be fine" the therapist will help the person to examine the current evidence, so that they develop a rational understanding of the situation, such as "yes, it is an uncertain situation, but prevention has saved many lives and the rates of recovery among those infected is very high". Additionally, the therapist might use normalization, behavioral activation with a particular focus on physical activities, lifestyle changes and stress, and sleep management to help the person.

CBT is recommended by the national guidelines to treat mental and emotional health problems in most developed nations. ${ }^{7,8}$ The effects of CBT have been studied for various disorders and health problems. ${ }^{9110}$ There is also evidence to suggest that $C B T$ delivered through the internet can directly help health problems." Third wave CBT approaches such as mindfulness and 
Acceptance and Commitment Therapy (ACT) have also been used to help those with chronic physical conditions. ${ }^{12} \mathrm{CBT}$ has also been adapted for use across cultures and sub-cultures. ${ }^{13,14}$

Most importantly, evidence from research suggests that $C B T$ can be used to increase resilience. ${ }^{15}$ Resilience, which is described as the ability to recover readily from adversity and individuals using positive emotions in adverse circumstances have been found to be resilient. ${ }^{16}$ It is evident from the literature that highly resilient individuals nurture their positive emotions proactively. ${ }^{16}$ This certainly has implications for managing stress, boredom, and change. As resilience has been associated with better coping with mental and physical health problems and healthy aging. ${ }^{17}$ There is evidence to suggest that resilience can act as a protective factor against the development of psychopathology among those facing challenges. ${ }^{18}$

Resilience impacts both the illness process and outcome in health. According to a systematic review, resilience plays an important role in the treatment of chronic diseases, such as diabetes, rheumatoid arthritis, juvenile idiopathic arthritis, systemic lupus erythematosus, and Chagas disease. ${ }^{19} \mathrm{~A}$ negative relationship between resilience and common mental disorders (depression, anxiety, and somatization) has also been suggested in the same systematic review. Another important finding of the review was the inverse correlation between resilience scores and the progression of various illnesses and an association of resilience with health promotional behaviour and quality of life. ${ }^{19}$

While several multimedia based or faceto-face programmes have assessed the usefulness of CBT for resilience in a variety of populations, ${ }^{20}$ it has not been used to build resilience in persons facing challenging situations to help ease their distress and to prevent the development of psychopathology. CBT is an ideal intervention for victims of humanitarian crises such as earthquakes, floods, wars related trauma, and pandemics as it is evidencebased, structured, low cost, and can be delivered in a variety of formats, including online platforms. There is an urgent need to develop and test CBT based programs that focus on building resilience that can be used on a public health level to help persons facing challenges at national or global levels. We, therefore, believe that developing and testing $\mathrm{CBT}$ based interventions to build resilience among those facing challenging situations is a need of time.

\section{REFERENCES}

I. Liu S, Yang L, Zhang C, Xiang Y-T, Liu $Z$, Hu S, et al. Online mental health services in China during the COVID19 outbreak. Lancet Psychiatr 2020 Apr;7(4):el7-el8. DOI: 10.1016/ S22I5-0366(20)30077-8.

2. WHO Novel Coronavirus (2019$\mathrm{nCoV})$ situation reports [Internet]. 2020 [Accessed on: March 24, 2020]. Available from URL: https://www. who.int/emergencies/diseases/novelcoronavirus-2019/situation-reports

3. Xiang Y-T, Yang Y, Li W, Zhang L, Zhang $\mathrm{Q}$, Cheung $\mathrm{T}$, et al. Timely mental health care for the 2019 novel coronavirus outbreak is urgently needed. Lancet Psychiatr 2020 Mar I;7(3):228-9. DOI: 10.1016/S22150366(20)30046-8.

4. Rhodes KV, Lauderdale DS, Stocking $\mathrm{CB}$, Howes DS, Roizen MF, Levinson $W$. Better health while you wait: A controlled trial of a computer-based intervention for screening and health promotion in the emergency department. Ann Emerg Med 200I Mar;37(3):284-9I.

5. Surico $P$, Galeotti $A$. The economics of a pandemic: the case of Covid-19 [Internet]. Wheeler Institute for Business and Development; 2020 [Accessed on: March 25, 2020]. Available from URL: https://icsb. org/the economicsofapandemic/

6. Beck AT, Rush AJ, Shaw BF, Emery G. Cognitive therapy of depression. ${ }^{\text {st }}$ ed. The Guilford Press, New York. 1979. pp. 425 .

7. American Psychiatric Association. Practice guideline for major depressive disorder in adults. Amer Psychiatric Pub Incorporated; 1993.

8. NICE. Depression in adults: recognition and management | Guidance and guidelines | NICE
[Internet]. 2016 [Accessed on: March 2I, 2020]. Available from URL: https:// www.nice.org.uk/guidance/cg90?unli $d=9529803502016121911959$

9. Morley S, Eccleston C, Williams A. Systematic review and meta-analysis of randomized controlled trials of cognitive behaviour therapy and behaviour therapy for chronic pain in adults, excluding headache. Pain 1999 Mar;80(I-2):I-13.

10. Moorey S, Greer S. Cognitive behaviour therapy for people with cancer. Second Edition. Oxford University Press, Oxford 2002. 232 s., 8 obr., 20 tab., ISBN 0-19-850866-2, cena 24,95 GBP.

II. Cuijpers P, van Straten A, Andersson G. Internet-administered cognitive behavior therapy for health problems: A systematic review. J Behav Med 2008 Apr I;3 I (2): I69-77.

12. Graham CD, Gouick J, Krahé C, Gillanders D. A systematic review of the use of Acceptance and Commitment Therapy (ACT) in chronic disease and long-term conditions. Clin Psychol Rev 2016 Jun;46:46-58. DOI: 10.1016/j.cpr. 2016.04.009.

13. Naeem F, Phiri P, Nasar A, Munshi T, Ayub M, Rathod S. An evidence-based framework for cultural adaptation of cognitive behaviour therapy: Process, methodology and foci of adaptation. World Cult Psychiatry Res Rev 20।6; I I:67-70.

14. Naeem F, Phiri P, Rathod S, Ayub M. Cultural adaptation of cognitivebehavioural therapy. B J Psych Adv 2019;000(000): I-9.

15. Padesky CA, Mooney KA. Strengthsbased cognitive-behavioural therapy: a four-step model to build resilience. Clin Psychol Psychother 2012 Aug; 19(4):283-90. DOI: 10.1002/ cpp. 1795

16. Tugade MM, Fredrickson BL. Resilient individuals use positive emotions to bounce back from negative emotional experiences. J Pers Soc Psychol 2004 Feb;86(2):320-33.

17. Färber F, Rosendahl J. The Association between resilience and mental health in the somatically ill. Dtsch Ärztebl Int 2018 Sep;II5(38):62I-7. DOI: I0. 3238/arztebl.2018.062I.

18. Arnetz J, Rofa Y, Arnetz B, Ventimiglia 
$\mathrm{M}$, Jamil $\mathrm{H}$. Resilience as a protective factor against the development of psychopathology among refugees. J Nerv Ment Dis 2013 Mar;20I(3): 167-72.
19. Cal SF, Sá LR, Glustak ME, Santiago MB. Resilience in chronic diseases: A systematic review. C Cogent Psychol 20I5 Dec 3I;2(I): I024928.

20. Helmreich I, Kunzler A, Chmitorz A,
König J, Binder H, Wessa M, et al. Psychological interventions for resilience enhancement in adults. Cochrane Database Syst Rev 2017; 2 : CDOI 2527. Attribution-Non Commercial 2.0 Generic License.

KMUJ web address: www.kmuj.kmu.edu.pk

Email address: kmuj@kmu.edu.pk 